\title{
Hypernatraemia as a cause of intracranial haemorrhage
}

\author{
N. R. C. ROBERTON and P. HOWAT \\ From the Department of Paediatrics, University of Oxford, John Radcliffe Hospital
}

\begin{abstract}
Roberton, N. R. C., and Howat, P. (1975). Archives of Disease in Childhood, 50, 938. Hypernatraemia as a cause of intracranial haemorrhage. $29 \mathrm{de}-$ finite intracranial haemorrhages and 4 suspected ones occurred during a 25 -month period during which 10072 live infants were born. There were 4 subdural haemorrhages (all fatal), 4 isolated subarachnoid haemorrhages ( 2 fatal), and 21 intraventricular haemorrhages (all fatal- 2 beyond the neonatal period). There was no evidence of a causal relation between intraventricular haemorrhage and either hypernatraemia or large sodium intakes. There were too few cases of other types of intracranial haemorrhage to draw any aetiological conclusions.
\end{abstract}

The recent study by Simmons et al. (1974) suggested that the restricted use of sodium bicarbonate in 1970-1971 was associated with a lower incidence of intracranial haemorrhage ( $\mathrm{ICH}$ ) when compared with more liberal use of bicarbonate in 1966-1967. Volpe (1974), in an accompanying editorial, pointed out that many of their conclusions were not justified, and Cole et al. (1974), in their more detailed study restricted to intraventricular haemorrhage (IVH), were unable to document such an association. We have therefore reviewed our experience over a 25 -month period ending 31 July 1974 to see if we could establish any relation between hypernatremia and $\mathrm{ICH}$.

\section{Material and methods}

Our routine management of sick low birthweight infants has been described (Davies et al., 1972). All such infants have indwelling umbilical arterial catheters, and because of the risk of apnoea following THAM (Roberton, 1970), sodium bicarbonate was the base routinely used. Boluses of the $8.4 \%$ solution were infused when necessary at approximately $1 \mathrm{ml} / \mathrm{min}$ to maintain $\mathrm{pH}_{\mathrm{a}} 7 \cdot>25$. Blood was analysed for sodium at least daily, and the sodium intake in $\mathrm{mEq} / \mathrm{kg}$ per $24 \mathrm{~h}$ was calculated from the sodium intake in milk (Shaw, Jones, and Gunther, 1973) plus the amount given intravenously as bicarbonate or dextrose saline.

We maintained our umbilical artery catheters with heparinized saline $(10 \mu \mathrm{m} / \mathrm{ml})$. After use, catheters were cleared by infusing $50 \%$ more heparinized saline than the internal volume of the catheter; $0.1 \mathrm{ml}$ of saline (containing $0.015 \mathrm{mEq} \mathrm{Na}$ ) would therefore be infused every time the catheter was used. This quantity has been ignored in our calculations of sodium intake.

Received 17 March 1975.

\section{Results}

We examined the records of infants who were born in the hospital who had (a) developed hypernatraemia $(\mathrm{Na}>150 \mathrm{mEq} / \mathrm{l})$ during the neontatal period, (b) received more than $8 \mathrm{mEq} / \mathrm{kg}$ during any 24 hours in the neonatal period, (c) developed any form of ICH detected clinically or at necropsy during the neonatal period.

During the study period 10072 infants were born, and 1501 were admitted to our special care baby: unit. 50 nonmalformed infants died, 44 had necropsy examinations, and 25 of these had some form of ICH. 4 were subdural haemorrhages, 2 were subarachnoid haemorrhages alone, and 19 were IVH. 2 surviving infants were diagnosed as having subarachnoid haemorrhages, and 2 other infants died later in infancy after a shunt operation for posthaemorrhagic hydrocephalus attributed to a neonatal IVH.

Four of the 6 infants who did not have a necropsy examination were thought on clinical evidence to have had an IVH. The birthweights of infants with IVH are given in Table I. 14 infants developed hypernatraemia, and 38 received more than $8 \mathrm{mEq} \mathrm{Na} / \mathrm{kg}$ per $24 \mathrm{~h}$. Their birthweights are given in Table II. The inter-relation between hypernatraemia, high sodium intake, and $\mathrm{ICH}$ is shown in Fig. 1. 12 of the 21 infants with IVH received more than $8 \mathrm{mEq} \mathrm{Na} / \mathrm{kg}$ per $24 \mathrm{~h}, 4$ of the 21 were hypernatraemic, but only 2 infants were hypernatraemic, received a high sodium intake, and had an ICH.

We also investigated the relation between IVH, hypernatraemia, and high sodium intake in all 
TABLE I

Cases of IVH

\begin{tabular}{l|c|c|c|c}
\hline \multicolumn{1}{c|}{ Birthweight (kg) } & IVH at necropsy & Clinical course suggesting IVH (no necropsy) & No. live born & \% with IVH \\
\hline$<1.0$ & 5 & 1 & 14 & 57 \\
$1.0 \mathrm{~kg}-<1.5$ & $8^{\star}$ & 3 & 131 & $19 \cdot 3$ \\
$1.5 \mathrm{~kg}-<2.0$ & 7 & - & 9870 & $5 \cdot 8$ \\
$>2.0$ & 1 & & 0.01 \\
\hline
\end{tabular}

*Including 2 infants dying after the neonatal period with hydrocephalus and evidence of an old IVH.

TABLE II

Incidence of hypernatraemia and high sodium intake at different birthweights

\begin{tabular}{|c|c|c|c|c|}
\hline \multirow[b]{2}{*}{ Birthweight (kg) } & \multicolumn{2}{|c|}{$>8 \mathrm{mEq} / \mathrm{kg}$ per $24 \mathrm{~h}$} & \multicolumn{2}{|c|}{ Hypernatraemia $>150 \mathrm{mEq} / \mathrm{l}$} \\
\hline & Alive & Dead & Alive & Dead \\
\hline $\begin{array}{l}<1 \cdot 0 \\
1 \cdot 0-<1 \cdot 5 \\
1 \cdot 5-<2 \cdot 0 \\
2 \cdot 0-<2 \cdot 5 \\
>2 \cdot 5\end{array}$ & $\begin{array}{l}1 \\
4 \\
2 \\
2 \\
2\end{array}$ & $\begin{array}{l}5 \\
7 \\
7 \\
2 \\
6\end{array}$ & $\begin{array}{c}4 \overline{(1)} \\
1 \\
1 \\
6\end{array}$ & $\begin{array}{l}4(2) \\
\frac{1}{1} \\
\frac{1}{1}(1)\end{array}$ \\
\hline
\end{tabular}

Figures in parentheses $=\mathrm{Na}>160 \mathrm{mEq} / \mathrm{l}$.
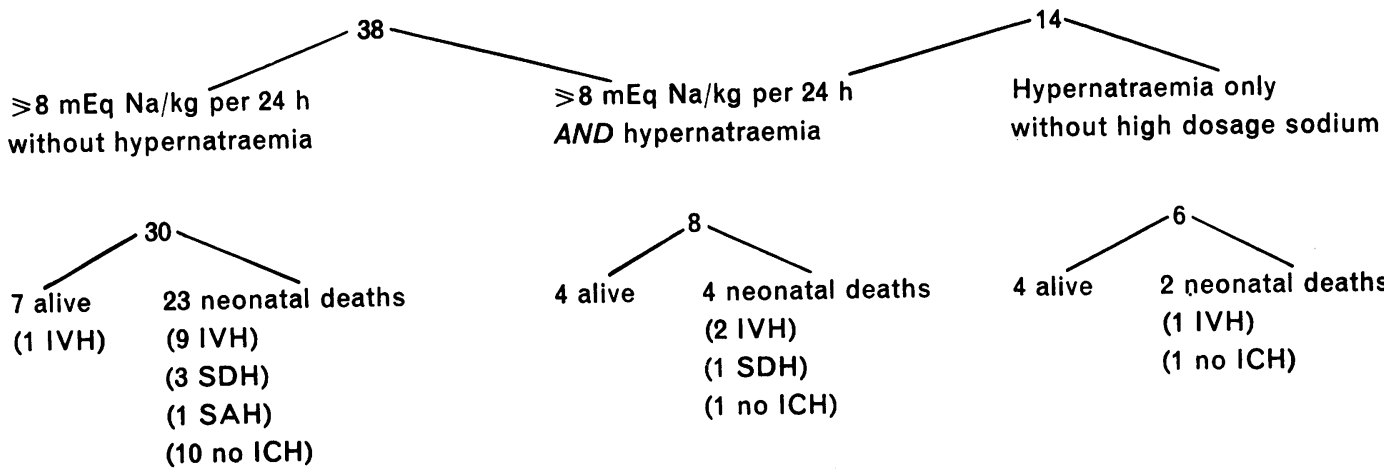

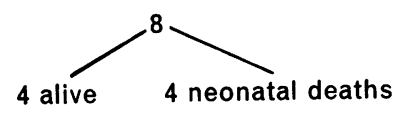

(2 IVH)

(1 SDH)

(1 no $\mathrm{ICH}$ )

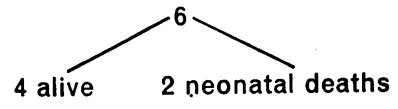

(1 IVH)

(1 no ICH)

FIG. 1.-Relation between ICH, hypernatraemia, and sodium administration at all birthweights. 8 infants with IVH and 3 with $S A H$ were neither hypernatraemic nor received $>8 \mathrm{mEq} N a / k g$ per 24 h. SAH, subarachnoid haemorrhage; SDH, subdural haemorrhage; IVH, intraventricular haemorrhage; ICH, intracranial haemorrhage.

infants between 1.0 and $2 \cdot 0 \mathrm{~kg}$ (Fig. 2 and 3 ). IVH was present in 15 of the 188 infants $(8.0 \%)$, and in 15 of the 21 nonmalformed infants on whom a necropsy was performed $(68 \%)$. There is no relation apparent between either factor and IVH. Furthermore, 6 of the 9 dead infants with IVH in the $>8 \mathrm{mEq} \mathrm{Na} / \mathrm{kg}$ per $24 \mathrm{~h}$ group received their sodium after the collapse attributed to the IVH.

The clinical details of the infants with subdural and subarachnoid haemorrhages are given in Table III. All of the infants with subdural haemorrhages were severely asphyxiated and $3 \mathrm{had}$ associated tentorial tears. Only one of the infants with subarachnoid haemorrhage received high doses of sodium, and he was critically ill with a group B $\beta$-haemolytic streptococcal septicaemia.

3 of the hypernatraemic infants had fits; 1 survived-an infant with a maximum sodium of 163 

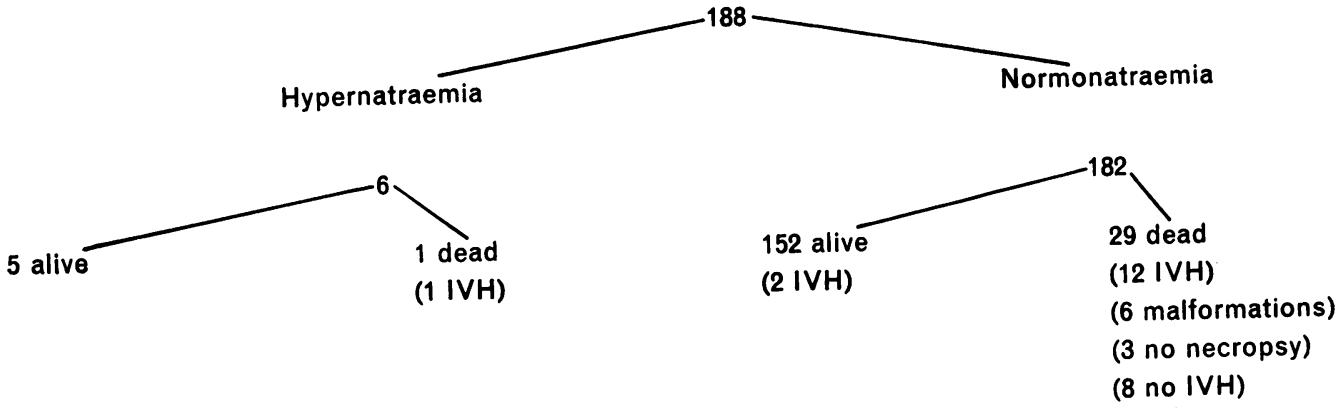

FIG. 2.-IVH in infants developing hypernatraemia. $1 \cdot 0-2 \cdot 0 \mathrm{~kg}$ birthweight only.
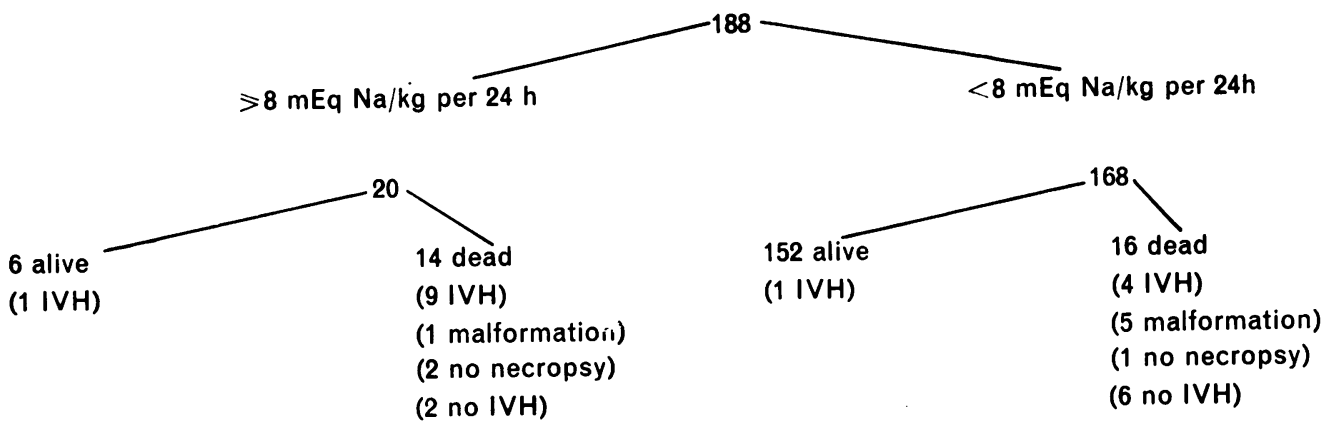

FIG. 3.-Infants receiving $>8 m E q \mathrm{Na} / \mathrm{kg}$ per $24 \mathrm{~h}$. 1.0-2.0 kg birthweight only.

TABLE III

Infants with subdural (SDH) and subarachnoid (SAH) haemorrhage

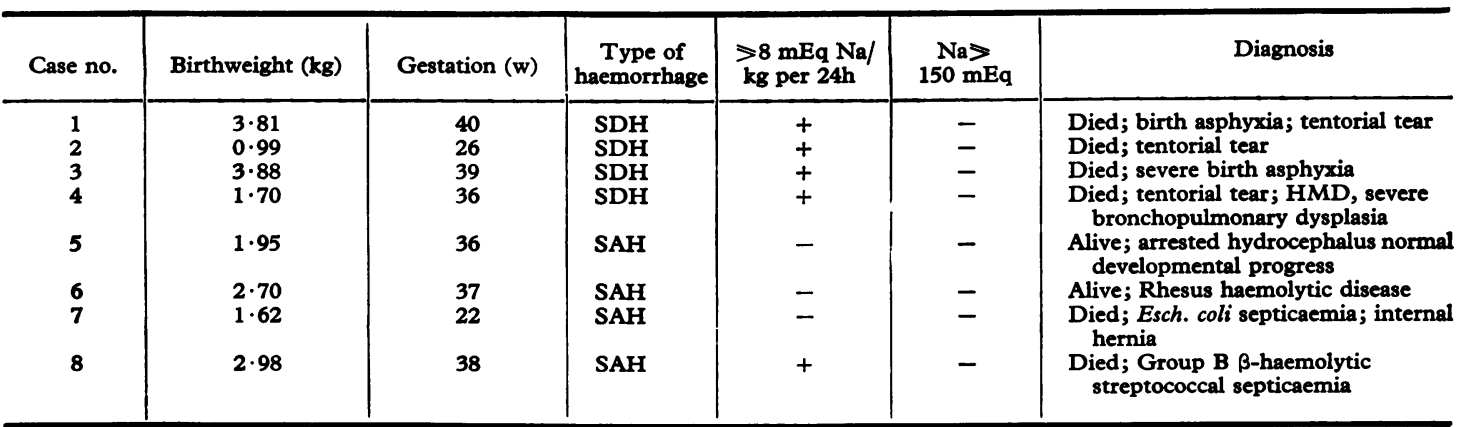

$\mathrm{mEq} / \mathrm{l}$. The fits in this infant were probably due to the hypernatraemia. The two other hypernatraemic infants with fits were a severely asphyxiated term infant, and a $800 \mathrm{~g}$ 26-week premature who had a horseshoe kidney and a massive IVH. 8 other infants who had IVH developed tonic fits terminally. All received high doses of sodium, but none were hypernatraemic.

\section{Discussion}

ICH is a major cause of neonatal death, but in any analysis of neonatal ICH it is very important to consider IVH in a separate category. The aetiology of IVH remains uncertain. However, its association with extreme prematurity has led most workers to conclude that hypoxia plays a major role. The capillaries in the highly vascular 
germinative zone overlying the basal ganglia are very susceptible to vascular stasis, thrombosis, rupture, and haemorrhage. In a sick infant this tendency may be aggravated by the increased capillary fragility of hypoxia and acidaemia, surges in central venous pressure, or arterial blood pressure coagulation disturbances, and perhaps by rapid alterations in plasma osmolarity (Cole et al., 1974; Hambleton and Wigglesworth, 1975.)

IVH is primarily a condition of very low birthweight infants (Table I) (Fedrick and Butler, 1970), and is very rare in infants weighing more than $2.0 \mathrm{~kg}$; the only such case in our series being an infant with an undiagnosed blood dyscrasis presenting shortly after birth with massive haemolysis, jaundice, thrombocytopenia, and petechial haemorrhages not due to fetal infection.

During the period of our study we have not changed our indications for giving bicarbonate. We are therefore not in a position to comment on a different incidence of IVH associated with decreasing use of intravenous base. However, we have found no correlation between sustained hypernatraemia and IVH, though the incidence of transient hypernatraemia will have been underestimated. Infusions of base cause transient surges of osmolarity which return to normal within 15 minutes (Baum and Roberton, 1975). We have also failed to show any association between large doses of sodium and IVH. The higher mortality rate in infants receiving large amounts of sodium was due to the severity of the illness since the lower the $p \mathrm{H}$ the larger the dose of sodium bicarbonate administered.

There may be several reasons for the different conclusions drawn by Simmons et al. (1974) and ourselves. Each type of neonatal ICH has a differing aetiology and pathogenesis. By considering all types of ICH together Simmons et al. (1974) may have masked the fact that there was no association between hypernatraemia and IVH. Infusions of hypertonic solutions which are prolonged or more rapid than $1 \mathrm{ml} / \mathrm{min}$ may cause ICH of the subdural subarachnoid, or petechial type but very rarely cause IVH (Luttrell and Finberg, 1959; Luttrell, Finberg, and Drawdy, 1959). Simmons et al. (1974) state that there was no evidence of trauma in their cases of subdural haemorrhage, so that these, and their cases of subarachnoid and petechial haemorrhage, may well have been due to overexuberant use of base. However, we had no cases with brain stem petechial haemorrhage, and our cases of subdural and subarachnoid haemorrhage were not due to excessive bicarbonate administration, since the infants either received no bicarbonate or received it after the damage was done by streptococcal septiceaemia or intrapartum asphyxia with a tentorial tear (Table III).

A number of other factors may have contributed to their reported decrease in ICH as a whole. They do not give details of the birthweight distribution of their nursery population in the two periods studied, nor the incidence of neonatal illnesses known to predispose to ICH of any form.

Furthermore, ICH, hypernatraemia, and large sodium intake, though present in the same infant, may not be causally related. Thus, after an IVH an infant becomes apnoeic, hypoxic, acidaemic, and shocked. In a vain attempt to resuscitate such infants large quantities of base may be given. In 6 of the 9 cases of IVH in our series where $>8$ $\mathrm{mEq} \mathrm{Na} / \mathrm{kg}$ per $24 \mathrm{~h}$ was given, it was given after such a collapse. In the other 3 bicarbonate was given partly for severe birth asphyxia and partly after the collapse attributed to the IVH. In infants with subdural haemorrhage an apparent association with hypernatraemia could also be explained by the base being given after a severely asphyxial delivery causing a tentorial tear.

Since we have failed to show any association between hypernatraemia, large sodium intake, and IVH, we feel that it is important to stress that infusions of base should not be withheld from acidemic infants because of an uproven risk of IVH. When a large base deficit is present after severe birth asphyxia, cardiac arrest, or severe apnoeic attacks, base should be given at a rate no faster than $1 \mathrm{mEq} / \mathrm{min}$ (Baum and Roberton, 1975). For the premature infant at risk from hyaline membrane disease, the prevention of acidaemia is particularly important since surfactant synthesis is $p \mathrm{H}$-dependant (Gluck et al., 1972). However, by not attempting correction to greater than $\mathrm{pH} 7 \cdot 25$, and by adequate maintenance of $\mathrm{PaO}_{2}$, haematocrit, and blood volume (Roberton, 1975) the use of base subsequently can and should be minimized.

We thank Professor J. P. M. Tizard for help in preparation of the manuscript; Drs. D. J. deSa, J. Skinner, and J. Keeling for necropsy examinations; and Mr. F. Gray and the Department of Chemical Pathology, John Radcliffe Hospital, for the sodium measurements.

\section{REFERENCES}

Baum, J. D., and Roberton, N. R. C. (1975). Immediate effects of infusion of base in infants with RDS. Fournal of Pediatrics, 87, 255.

Cole, V. A., Durbin, G. M., Olaffson, A., Reynolds, E. O. R., Rivers, R. P. A., and Smith, J. F. (1974). Pathogenesis of intraventricular haemorrhage in newborn infants. Archives of Disease in Childhood, 49, 722. 
Davies, P. A., Robinson, R. J., Scopes, J. W., Tizard, J. P. M., and Wigglesworth, J. S. (1972). Medical Care of Newborn Babies. (Clinics in Developmental Medicine No. 44/45.) Heinemann, London.

Fedrick, J., and Butler, N. R. (1970). Certain causes of neonatal death. II. Intraventricular haemorrhage. Biologia Neonatorum, 15, 257.

Gluck, L., Kulovich, M. V., Eidelman, A. I., Cordero, L., and Khazin, A. F. (1972). Biochemical development of surface activity in mammalian lung. Pediatric Research, 6, 81.

Hambleton, G., and Wigglesworth, J. S. (1975). Vascular studies on premature brain. (Abst.) Archives of Disease in Childhood, 50, 744.

Luttrell, C. N., and Finberg, L. (1959). Hemorrhagic encephalopathy induced by hypernatremia. A.M.A. Archives of Neurology and Psychiatry, 81, 424.

Luttrell, C. N., Finberg, L., and Drawdy, L. P. (1959). Hemorrhagic encephalopathy induced by hypernatremia. Archives of Neurology, 1, 153.
Roberton, N. R. C. (1970). Apnoea after THAM administration in the newborn. Archives of Disease in Childhood, 45, 206.

Roberton, N. R. C. (1975). Pulmonary disease in the neonate and infancy. In Recent Advances in Respiratory Disease. Ed. by T. H. Shelton. Churchill, London. (In press.)

Shaw, J. C. L., Jones, A., and Gunther, M. (1973). Mineral content of brands of milk for infant-feeding. British Medical fournal, 2, 12.

Simmons, M. A., Adcock, E. W., Bard, H., and Bataglia, F. C. (1974). Hypernatremia, intracranial hemorrhage and $\mathrm{NaHCO} 3$ in neonates. New England Yournal of Medicine, 291, 6.

Volpe, J. (1974). Neonatal intracranial hemorrhage-iatrogenic etiology? New England fournal of Medicine, 291, 43.

Correspondence to Dr. N. R. C. Roberton, Department of Paediatrics, Addenbrooke's Hospital, Hills Road, Cambridge CB2 2QQ. 